\title{
Correction to: The Effect of What We Think may Happen on our Judgments of Responsibility
}

\author{
Felipe De Brigard ${ }^{1}$ • William J. Brady ${ }^{2}$
}

Published online: 17 March 2018

(C) Springer Science+Business Media B.V., part of Springer Nature 2018

\section{Correction to: Rev Phil Psych \\ https://doi.org/10.1007/s13164-013-0133-8}

On pages 263, 265, and 266, incorrect degrees of freedom and t values were reported. The statistical conclusions are not affected by these reporting errors, but the corrected values are shown below.

p. 263: $t(26)=9.605, p<.001$ should read $t(52)=5.31, p<.001$

p. 265: $t(23)=12.145, p<.001$ should $\operatorname{read} t(48)=-2.56, p=.014$

p. 266: $t(22)=9.900, p<.001$ should read $t(46)=-3.31, p=.002$

Felipe De Brigard

brigard@wjh.harvard.edu

1 Department of Psychology, Harvard University, 860 William James Hall 33 Kirkland St., Cambridge, MA 02139, USA

2 Department of Psychology, New York University, New York, NY, USA 